\title{
Correction to: LINC00858 knockdown inhibits gastric cancer cell growth and induces apoptosis through reducing WNK2 promoter methylation
}

\author{
Jiang $\mathrm{Du}^{1} \cdot$ Yuan Liang ${ }^{2} \cdot \mathrm{Ji} \mathrm{Li}^{1} \cdot$ Jin-Ming Zhao ${ }^{1} \cdot$ Xu-Yong Lin ${ }^{1}$ \\ Published online: 19 November 2020 \\ (C) International Society for Cellular Oncology 2020
}

\section{Correction to: Cell Oncol.}

https://doi.org/10.1007/s13402-020-00518-4

The original version of this article mistakenly stated that $\mathrm{Dr}$ Zhen-Ning Wang was an author. Dr Zhen-Ning Wang was not involved with this paper and has therefore requested that his name be removed.

Publisher's note Springer Nature remains neutral with regard to jurisdictional claims in published maps and institutional affiliations.

Xu-Yong Lin

linxuyong@hotmail.com

1 Department of Pathology, The First Affiliated Hospital and College of Basic Medical Science, China Medical University,

Shenyang 110001, People's Republic of China

2 Medical Oncology Department of Thoracic Cancer (2), Cancer Hospital of China Medical University, Liaoning Cancer Hospital \& Institute, Shenyang 110042, People's Republic of China 